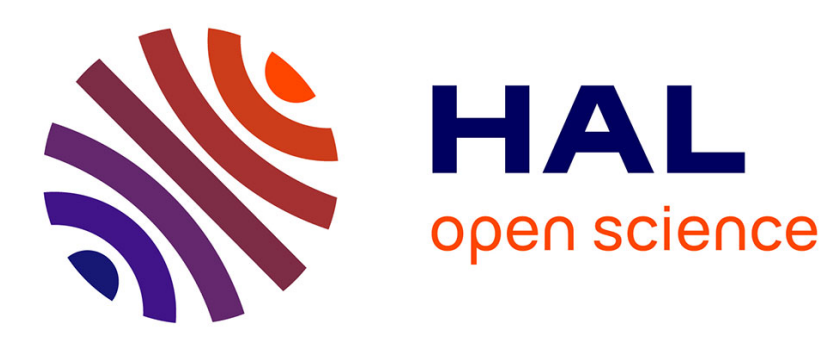

\title{
Berkeley-Madonna implementation of Ikeda's model
}

\author{
Julie Fontecave Jallon, Pierre Baconnier
}

\section{To cite this version:}

Julie Fontecave Jallon, Pierre Baconnier. Berkeley-Madonna implementation of Ikeda's model. International Conference of the IEEE Engineering in Medicine and Biology Society, Aug 2007, France. pp.582-585. hal-00373463

\section{HAL Id: hal-00373463 \\ https://hal.science/hal-00373463}

Submitted on 6 Apr 2009

HAL is a multi-disciplinary open access archive for the deposit and dissemination of scientific research documents, whether they are published or not. The documents may come from teaching and research institutions in France or abroad, or from public or private research centers.
L'archive ouverte pluridisciplinaire HAL, est destinée au dépôt et à la diffusion de documents scientifiques de niveau recherche, publiés ou non, émanant des établissements d'enseignement et de recherche français ou étrangers, des laboratoires publics ou privés. 


\title{
Berkeley-Madonna Implementation of Ikeda's Model
}

\author{
J. Fontecave-Jallon and P. Baconnier
}

\begin{abstract}
Starting from one model, we check the possibility of using Berkeley-Madonna software to transpose and simulate some existing biological integrated models. The considered model is the one of Ikeda et al., proposed in 1979, which treats of fluid regulation and which is very well described mathematically in the original paper. Despite a few mistakes or bugs, the model has been easily and successfully implemented under Berkeley-Madonna. We recover the same simulation results as Ikeda and new simulations can now easily be carried out, thanks to the user-friendly qualities of Berkeley-Madonna.
\end{abstract}

\section{INTRODUCTION}

$\mathrm{D}$ ESPITE the development of ever more sophisticated models at many scales, there does not seem to be for now, a comprehensive, organism-level environment, available for inspection, modification and extension. In that context, a current project, called SAPHIR and involved in the general effort of the IUPS Physiome project, aims at developing a comprehensive, modular, interactive modelling environment centred on overall regulation of blood pressure and body fluids. This model is expected to allow exploration of the whole chain of regulatory influences brought into play by a local perturbation such as a defect in a cell membrane ion transport protein. Two legacy models are the basis of this project. The first one is the work of Guyton et al. in 1972 [1] who treated overall regulation of blood pressure and constructed a model for the purpose of revealing the causes of hypertension. The second model is the one of Ikeda et al. in 1979 [2] and treats of fluid regulation.

The question of the model's implementation is central and the present article aims at showing the possibility of transposing one existing model under Berkeley-Madonna software [3]. Berkeley-Madonna is a fast and convenient differential equation solver, used to model and analyze dynamic systems. It has the advantage of being user-friendly and easily useable, especially for physiologists who are not always experimented in computer programming.

After a brief description of the Ikeda's model (in part II), we detail, in part III, the implementation of that model in Berkeley-Madonna and we show that it is feasible; after the correction of many bugs, we recover the same simulation

Manuscript received April 2, 2007. This work is part of the SAPHIR project (ANR Biosys 2006-2009): a Systems Approach for PHysiological Integration of Renal, cardiac and respiratory functions.

Julie Fontecave-Jallon is with the PRETA Team (Physiologie Respiratoire Expérimentale Théorique et Appliquée), TIMC, Faculté de Médecine, $38706 \mathrm{La}$ Tronche cedex, France (phone: +33(0)456.52.00.57; fax: +33(0)456.52.00.33; e-mail: Julie.Fontecave@imag.fr).

Pierre Baconnier is with the PRETA Team, TIMC, Faculté de Médecine, 38706 La Tronche cedex, France (e-mail: Pierre.Baconnier@imag.fr). results as in the original paper (part IV). At last, part V opens the discussion and especially the possibility of new simulations, thanks to Berkeley-Madonna's easy use.

\section{DESCRIPTION OF THE MODEL}

In 1979, Ikeda, Marumo, Shirataka and Sato propose, in Annals of Biomedical Engineering, an integrated model " $a$ model of overall regulation of body fluids," completely described mathematically and which makes a complement to Guyton-type model. Ikeda et al. aim at providing a biological system model, comprehensive and containing subsystems of circulation, respiration, body fluids, renal function, and acidbase balance. This model of body-fluid regulation is considered to study problems concerning body fluid disturbances and fluid therapy.

It consists of seven blocks classified into three categories. For each block, inputs come either from the other blocks of the model, or they are fixed or constant parameters. Concerning the outputs, some affect the other blocks of the model and some are independent of the other blocks. According to the authors, this partition was made so as to minimize the interaction between blocks.

The three categories consist each of one or several blocks.

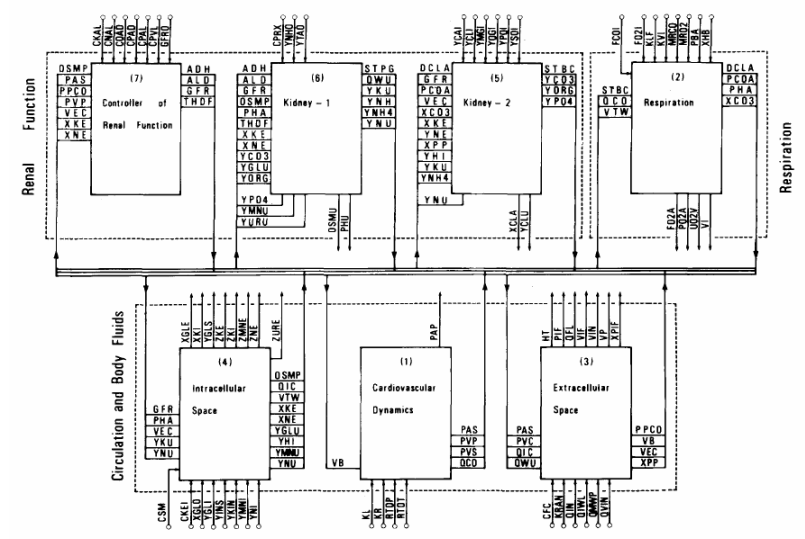

Fig. 1: Block-diagram of Ikeda's model [2].

\section{A. Circulation and body fluids}

This category contains the blocks 1, 3, and 4, which respectively correspond to the cardiovascular system, the extracellular and intracellular spaces and electrolytes.

In cardiovascular system block, the steady-state values of cardiac output and of the mean pressures in systemic arteries and veins and in pulmonary artery and vein are calculated as linear functions of the circulatory blood volume, on the basis of the Starling mechanism's linear approximation. The model is concerned only with normal states of the heart. 
Block 3 deals with water intake and output, and with the distribution of extracellular fluid. This block also represents the proteins flow in plasma and interstitial fluid.

Block 4, related to intracellular space, deals with the dynamics of the intracellular fluid volume and with the intracellular acid-base balance. Concentrations of sodium, potassium, glucose, urea and mannitol are calculated. This block is more detailed than in Guyton's model [1]: indeed Ikeda et al. wanted a model for explaining the findings in experimental metabolic acidosis and alkalosis.

In [2], the circulatory subsystem is simplified in relation to [1]: steady-state values are given by neglecting rapid transients such as autoregulation or stress relaxation.

\section{B. Respiration}

The respiration category consists of the respiratory system only (Block 2 of the model). This corresponds to the controlling and the controlled systems of respiration and the acid-base balance in blood. The alveolar ventilation is calculated as a function of $\mathrm{pH}$ and pressures of $\mathrm{CO}_{2}$ and $\mathrm{O}_{2}$ in blood. These partial pressures in arterial blood as well as in alveoli and the concentrations of $\mathrm{CO}_{2}$ and $\mathrm{O}_{2}$ in arterial and venous blood are evaluated in this block thanks to dynamics relations.

Ikeda et al. have derived this respiratory subsystem from a detailed model and their model thus takes into account the acid-base balance subsystem, contrary to Guyton's model.

\section{Renal function}

The renal function, which was relatively simple in Guyton's model, is more detailed in Ikeda. It is composed of three blocks: the blocks 5 and 6 (related to the kidney) and the block 7 which is the controller of the renal function.

Block 5 deals with the renal excretion rate for bicarbonate, calcium, magnesium, phosphate, sulphate and organic acids, according to the Tm-limited mechanism for reabsorption. The chloride excretion rate is also calculated.

Reabsorption and excretion of water, sodium and potassium, involved in the kidney system are represented in block 6 . The excretion rates of ammonia and titratable acid are also determined in that block. The $\mathrm{pH}$ of urine is calculated from the excretion rates of phosphate and organic acid according to the Henderson-Hasselbalch equation.

At last, block 7 gives the glomerular filtration rate and the control signals which operate on the kidney, such as the antidiuretic hormone or aldosterone. The mechanism of the renin-angiotensin-aldosterone system is not detailed.

\section{IMPLEMENTATION OF THE MODEL}

\section{A. Mathematical description of Ikeda's Model}

The Ikeda's model has the great advantage of being completely mathematically described in the original paper. Indeed, symbols used for variables and parameters are explained and normal values are given. Moreover the model is entirely drawn with a block diagram (Fig. 1), defining the global structure, and with several schemes to specify each part (one example is shown Fig. 2). In appendix, symbols used for drawing the model are detailed and the main functions are expressed mathematically.

Ikeda et al. used experimental results from the literature to set the parameters values, but also supplementary experiments. The model assumes a healthy human male of approximately $55 \mathrm{~kg}$ in weight.

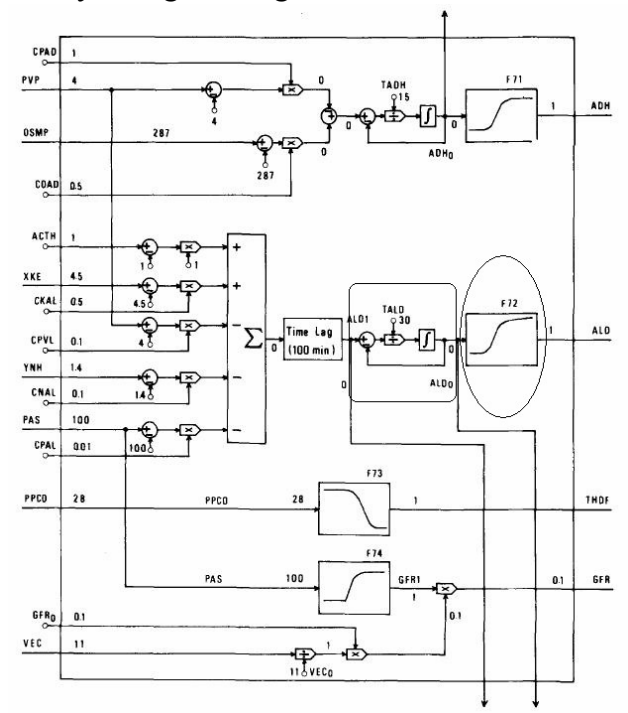

Fig. 2: Block 7 of Ikeda's model [2]: Controller of renal function.

This model is defined by more than 200 variables and it consists of about 130 non-linear differential or algebraic equations. Some of these equations are immediately available, thanks to their mathematical expressions; this is the case for example of the circled part in Fig. 2, whose expression is defined as F71 (below, with ALD related to the effect of aldosterone). Other equations are tacitly obtained thanks to the various blocks schemes; one example is given on (2), corresponding to the squared part in Fig. 2.

$$
\begin{aligned}
& A L D=\frac{10}{1+\exp (-0.4394(A L D 0-5))} \\
& \frac{d(A L D 0)}{d t}=\frac{A L D 1-A L D 0}{T A L D}
\end{aligned}
$$

\section{B. Berkeley-Madonna Implementation}

The model was initially written in Fortran IV language. We propose here an implementation with BerkeleyMadonna, which, as said before, is a fast and convenient differential equation solver, used to model and analyze dynamic systems.

This implementation has been carried out: the programming language is simple and close to the mathematical expressions, and the complete transposition of the Ikeda's model under Berkeley-Madonna has been realized with success.

However we have detected some bugs and mistakes in the original paper [2] and spent time to correct them. Among them and without being thorough, we find, for example, 
continuity problems in mathematical expressions (such as F31 or F74). There are also incoherencies between formulas explicitly written in the original article and symbols in the blocks' schemes (especially, problems of signs) and incoherencies between the normal values displayed on the blocks and the ones listed in appendix.

Once implemented and corrected, the model behaviour can be simulated, by simply imposing the values of such or such input variables. This allows checking that we recover the simulations results previously obtained by the authors.

\section{RESULTS OF SIMULATIONS}

Simulated responses to various inputs are carried out under Berkeley-Madonna. We follow the simulations achieved in the original paper so as to evaluate the rightness of our programmed equations and we compare our results with the original ones. These latter were initially set against existing experimental data from the literature, in order to show that the model behaviour was in good agreement with a number of experimental results pertaining to body fluid and acid-base disorders.

Three simulations are presented here: responses to water loading, $\mathrm{CO}_{2}$ inhalation and glucose infusion. The curves can be observed on next page, in Fig. 3.

\section{A. Response to water loading}

For their first simulation, Ikeda et al. realized one of the most fundamental tests of the interaction between body fluids and the kidney, that is to say, water loading. Therefore we also simulate the oral intake of water at a rate of $1000 \mathrm{ml}$ per 5 minutes (drinking rate $\mathrm{QIN}=0.2 \mathrm{l} / \mathrm{min}$ from $\mathrm{t}=5 \mathrm{~min}$ to $\mathrm{t}=10 \mathrm{~min}$ ). The responses observed (Fig. $3 \mathrm{a}$ ) are the urinary output (QWU), the plasma volume (VP), the volumes of extracellular (VEC), intracellular (VIC) and interstitial (VIF) fluids, and also the osmolality (OSMP), the standard bicarbonate at $\mathrm{pH}=7.4$ (STBC), the systemic arterial pressure (PAS) and the effects of antidiuretic hormone (ADH) and aldosterone (ALD). These responses, over 3 hours, are very close to the original paper ones (Fig. 3d, from Fig. 10 in [2]).

\section{B. Respiratory responses to increased $\mathrm{CO}_{2}$ concentration in inspired air}

In this part, we simulate, during 1 hour, the transient response of the respiratory parameters to the inhalation of $5 \% \mathrm{CO}_{2}$ in air during 30 minutes $(\mathrm{FCOI}=0.05$ from $\mathrm{t}=5 \mathrm{~min}$ to $\mathrm{t}=35 \mathrm{~min})$. We observe the alveolar ventilation (VI), the pressure of $\mathrm{CO}_{2}$ and $\mathrm{O}_{2}$ in alveoli (PCOA and PO2A) and the concentration of bicarbonate of the extracellular fluid (XCO3). The results, presented Fig. 3b, are compared with the original, in Fig. 3e (scanned from Fig. 11 in [2]). There are great similarities between both simulations.

\section{Glucose metabolism and Potassium}

According to the simulation realized by Ikeda et al., we simulate the response of the system to the infusion of $50 \mathrm{~g}$ glucose in 50 minutes ( $Y G L I=1 \mathrm{~g}$ from $\mathrm{t}=5 \mathrm{~min}$ to $\mathrm{t}=55 \mathrm{~min}$ ).
As Ikeda, we observe (Fig. 3c) the simulated concentrations of glucose (XGLE) and potassium (XKE) of extracellular fluid, the plasma osmolality (OSMP), the urine output (QWU) and the renal excretion rates of glucose (YGLU) and of potassium (YKU). Our predictions, over 3 hours, are very similar to those obtained in 1979 (Fig. 3f or Fig. 12 in [2]).

Other simulations are described in the original paper [2] and they have also been carried out under BerkeleyMadonna. The results thus obtained are again the same as the ones obtained by Ikeda et al.

\section{DISCUSSION}

All those results show that we recover well the original responses simulated by the authors of the model. This allows us to conclude that this Berkeley-Madonna implementation simulates correctly the model's behavior.

In the original paper, the authors give examples of application to clinical problems in the diagnosis and therapy of body fluid balance and discuss the possibilities for simulating some pathological states by this model, in order to consider this model as a useful framework for physiological experimental research.

Thanks to the model's successful implementation under Berkeley-Madonna, those sorts of simulations are possible. Several new conditions can be easily tested out, starting from the user-friendly interface of the software. For example, the possibility of defining sliders to vary the value of either parameter is offered. Moreover, time computation of the model is fast: a few seconds are required to simulate the model behaviour during several hours. At last, this software can be used without any weighty knowledge of computer programming.

However, this model does not completely describe the overall regulation of blood pressure and body fluids. Even if some aspects existing in Ikeda's model are not represented in Guyton [1] (such as the $\mathrm{pH}$ of blood or urine, the ventilation or the $\mathrm{CO}_{2}$ functions), there are also some Guyton's elements which are not followed in Ikeda. For example, the Guyton's model takes into account several dynamics; it is interested in autoregulation and stress relaxation, which is not the case of Ikeda's model. A comparison study is currently carried out between both models.

Acknowledgment: The present study is supported by Agence Nationale de la Recherche (ANR).

\section{REFERENCES}

[1] A.C. Guyton, T.G. Coleman, and H.J. Granger, "Circulation: overall regulation”, Annual Review of Physiology, vol: 34, 1972, pp. 13-46.

[2] N. Ikeda, F. Marumo, M. Shirataka, and T. Sato, "A model of overall regulation of body fluids", Annals of Biomedical Engineering, vol: 7, 1979, pp. 135-166.

[3] R. Macey, and G. Oster.. "Berkeley-Madonna: Modeling and Analysis of Dynamic Systems" (v.8.3.9). University of California, Berkeley. [Online]. Available: http://www.berkeleymadonna.com/ 


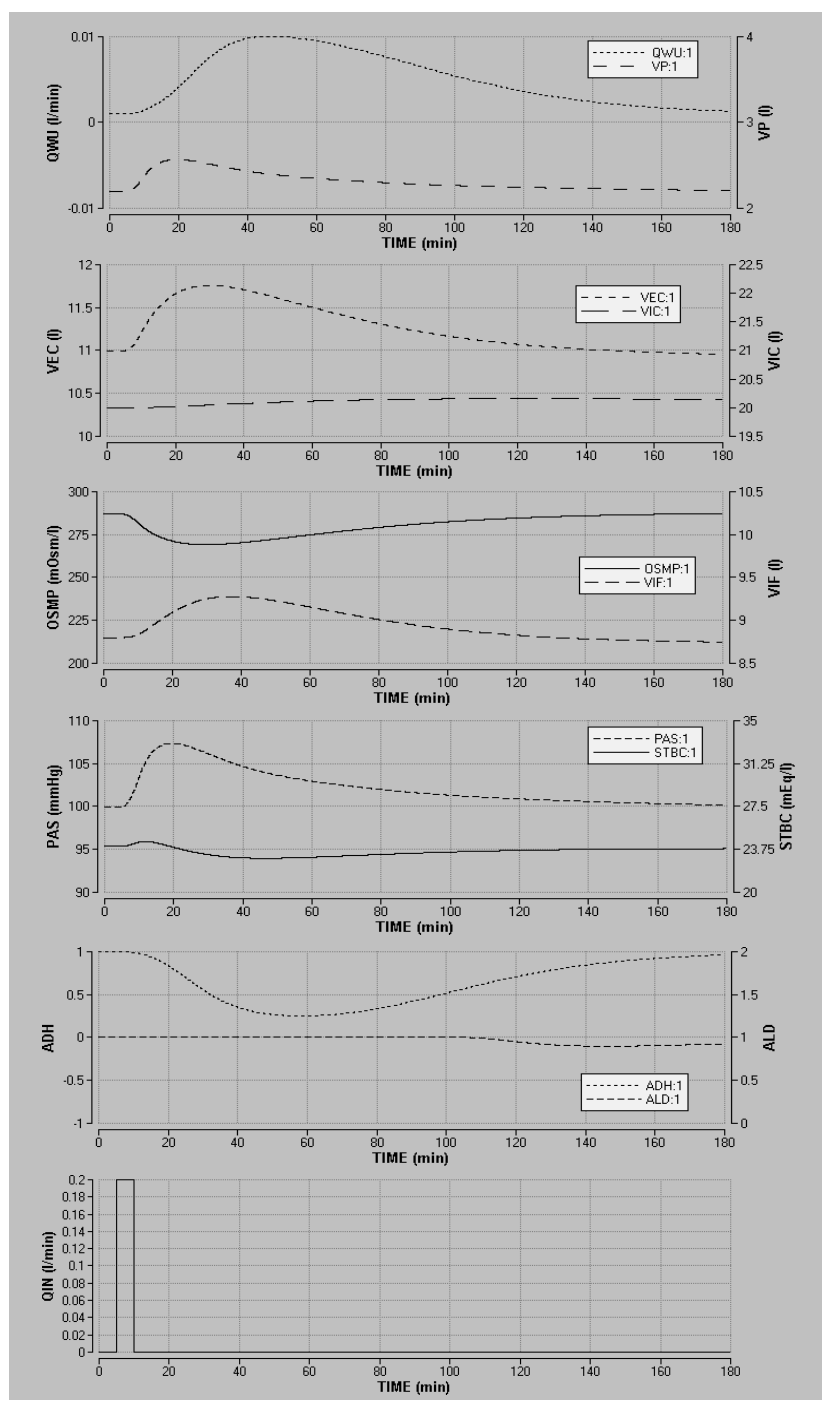

(a): Berkeley-Madonna's simulation of acute water loading

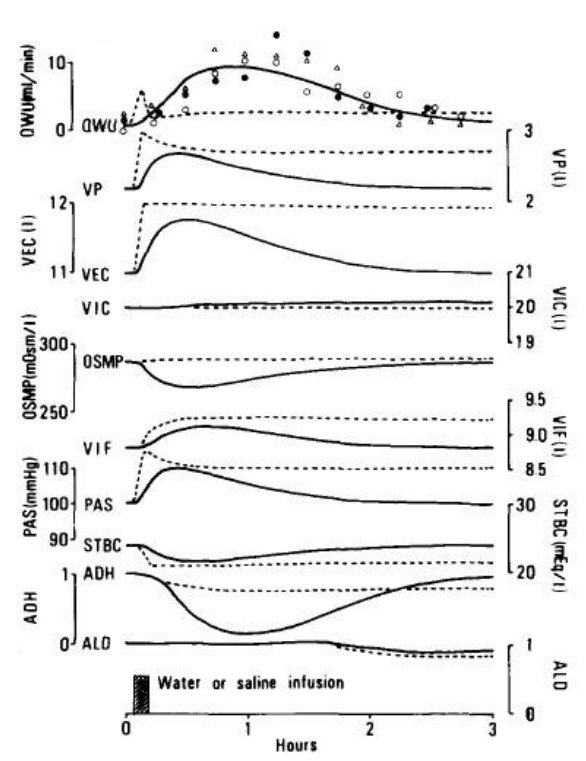

(d): Ikeda's simulation (Fig. 10 of [2]) of acute water loading (in black lines)
Fig. 3: Comparison between original Ikeda's simulation results and our simulated responses to various inputs under Berkeley-Madonna.

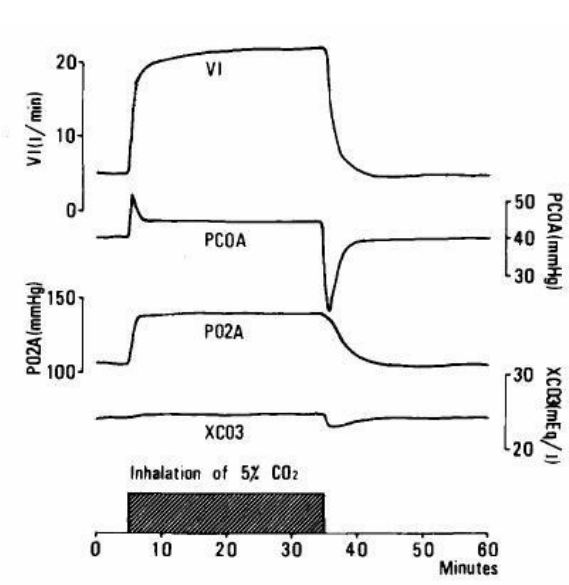

(e): Ikeda's simulation (Fig. 11 of [2]) of $\mathrm{CO}_{2}$ inhalation
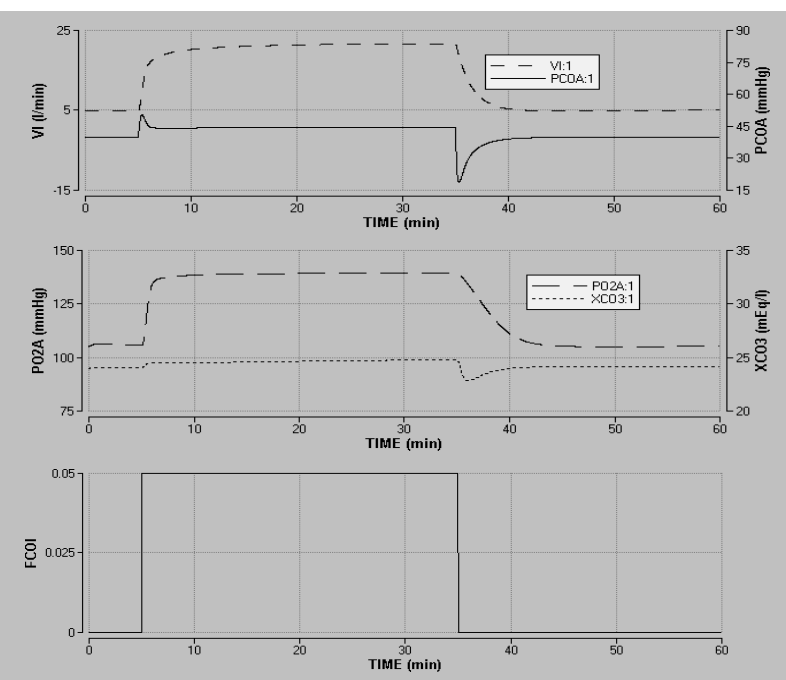

(b): Berkeley-Madonna's simulation of $\mathrm{CO}_{2}$ inhalation
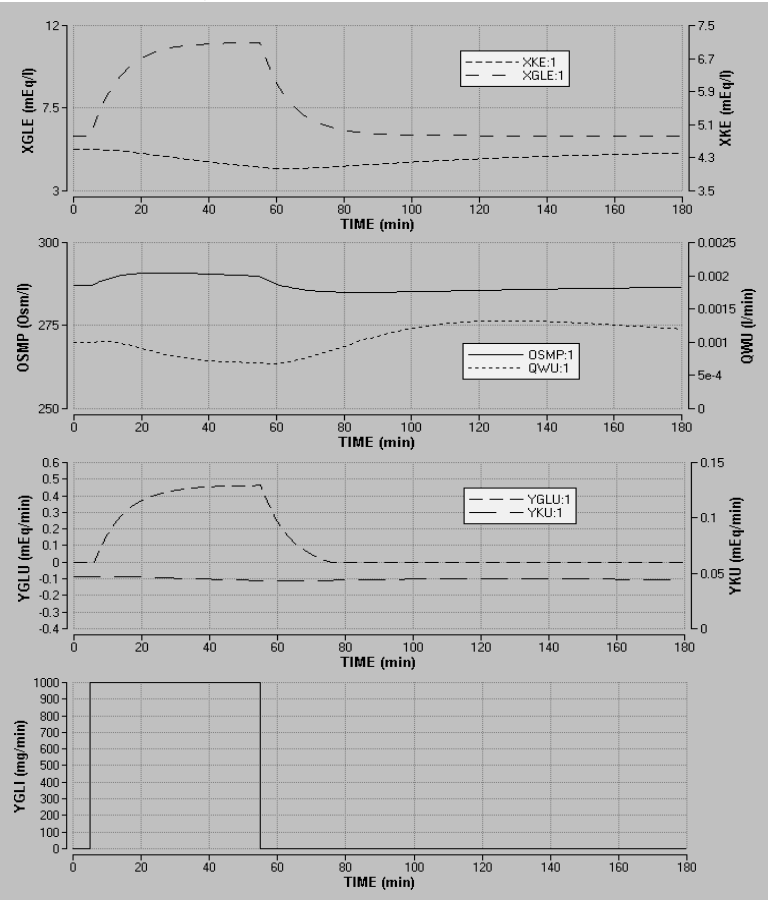

(c): Berkeley-Madonna's simulation of glucose infusion

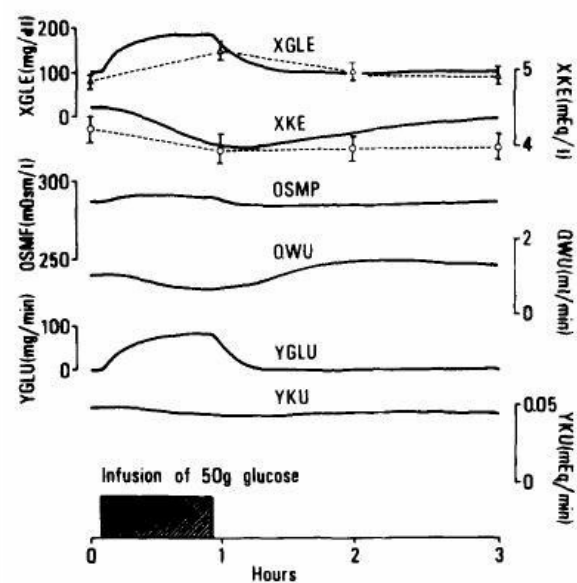

(f): Ikeda's simulation (Fig. 12 of [2]) of glucose infusion 